\title{
Tecnologias sociais para o desenvolvimento da pecuária leiteira no Assentamento Rural Rio Feio em Guia Lopes da Laguna, MS, Brasil
}

\author{
Social technologies for the development of dairy cattle in Rio Feio Settlement in Guia \\ Lopes da Laguna, MS, Brazil
}

\section{Technologies sociales pour le développement de bovins laitiers dans l'établissement Rural à Rio Feio, Guia Lopes da Laguna, MS, Brazil}

Tecnologías para el desarrollo del la ganaderia lechera en Asentamiento Rural Rio Feio, Guia Lopes da Laguna, MS, Brazil

\author{
Andre Rozemberg Peixoto Simões* \\ (andrerpsimoes@hotmail.com) \\ Marcus Vinicius Morais de Oliveira* \\ (marcusvinicius@hotmail.com) \\ Dario de Oliveira Lima-Filho** \\ (dariolimafilho@gmail.com)
}

Recebido em 04/11/2013; revisado e aprovado em 10/08/2014; aceito em 24/09/2014

DOI: http://dx.doi.org/10.1590/1518-70122015114

\begin{abstract}
Resumo: Com o objetivo de incrementar a eficiência técnica da atividade leiteira de um grupo de 30 produtores de origem familiar, foi realizada assistência técnica durante 12 meses com foco na intensificação do uso das pastagens. A experiência foi realizada no município de Guia Lopes da Laguna, em Mato Grosso do Sul. Constatou-se resistência na aceitação de algumas tecnologias por diversos fatores, entretanto, nas propriedades que seguiram as recomendações, observou-se aumento de $413 \%$ da produtividade da terra (l/ha/ano).

Palavras-chave: Bovinocultura leiteira. Assistência técnica. Agricultura familiar.

Abstract: Aiming to increase the technical efficiency of dairy cattle herds from a group of 30 family farmers, were offered to them, technologies based on intensive use of pasture along 12 months. The experience was developed at Guia Lopes da Laguna county, Mato Grosso do Sul State, Brazil. As result, was noticed that the farmers have resistance of adopting new technologies explained by many factors. However, them that followed the recommendations had an increase of $413 \%$ of the land productivity (1/ha/year).

Key words: Dairy cattle. Technical assistance. Family farming.

Resumé: Dans le but d'accroître l'efficacité technique des produits laitiers d'un groupe de 30 producteurs d'origine familiale, il a été proposé une assistance technique pendant 12 mois en mettant l'accent sur l'une utilisation accrue des pâturages. L'expérience a été menée dans la communauté de Guia Lopes da Laguna, à la province de Mato Grosso do Sul. Il a été trouvé une résistance dans l'acceptation de certaines technologies causé par plusieurs facteurs, cependant, dans les propriétés qui ont suivi les recommandations, il y a eu une augmentation de $413 \%$ de la productivité des terres (l/ha/an).

Mots clés: Bovins laitiers. Assistance technique. L'agriculture familiale.

Resumen: Con el objetivo de incrementar la eficiencia técnica de la actividad lechera de un grupo de 30 productores de la agricultura familiar, fue realizada asistencia técnica durante 12 meses con foco en la intensificación del uso de las pasturas. La experiencia fue realizada en el municipio de Guia Lopes da Laguna en Mato Grosso do Sul. Fue constatada resistencia en la aceptación de algunas tecnologías por diversos factores, mientras que, en las propiedades que siguieron las recomendaciones, fue observado aumento de $413 \%$ de la productividad de la tierra (1/ha/año). Palabras clave: Agricultura familiar. Asistencia técnica. Ganado lechera.
\end{abstract}

\section{Introdução}

O Brasil ocupa o quarto lugar na produção mundial de leite, com 32 bilhões de litros por ano, ficando atrás apenas dos Estados Unidos, Índia e China com produções anuais de 89,52 e 36 bilhões, respectivamente. Entretanto essa vantagem é sustentada devido ao grande número de animais em produção; são cerca de 23 milhões de vacas, perdendo apenas para a Índia, onde a vaca é considerada um animal sagrado. Esse fato fica mais evidente quando se observam os índices de produtividade das vacas em lactação, que no Brasil é de 1.382 litros/vaca/ano, enquanto que nos Estados Unidos e China são de 9.678 e

\footnotetext{
* Universidade Estadual de Mato Grosso do Sul (UEMS), Campo Grande, MS, Brasil.

** Universidade Federal de Mato Grosso do Sul (UFMS), Campo Grande, MS, Brasil.
} 
3.003litros/vaca/ano, respectivamente (IBGE, s.d.; FAO, s.d.).

No Brasil, a cadeia produtiva do leite é grande geradora de empregos, renda e tributos, sendo a bovinocultura leiteira vital para o desenvolvimento do setor primário da economia, devido ao uso intensivo de mão de obra e por ser o sustento de milhares de famílias que vivem no meio rural, desempenhando uma importante função socioeconômica (MADALENA, 2001). Embora a atividade leiteira seja um ativo gerador de renda mensal para os produtores, em realidades de agricultura familiar e de assentamentos a produção e produtividade são menores quando comparadas com a produção empresarial, especialmente e Mato Grosso do Sul (WEIVERBERG; SONAGLIO, 2010).

Assim, produção brasileira de leite ainda tem muitos aspectos a serem melhorados, principalmente no que concerne à sanidade e melhoramento genético do rebanho, ao manejo das pastagens e às estratégias de suplementação alimentar durante o período de estiagem, bem como nos aspectos relacionados à qualidade do leite ordenhado e ao gerenciamento administrativo e financeiro da atividade.

Em 2012, o estado de Mato Grosso do Sul produziu cerca de 530 milhões de litros de leite, colocando-o na posição de $13^{\circ}$ lugar no ranking nacional, e com uma produtividade média de 984 litros/vaca/ano (IBGE, s.d.). É válido ressaltar, ainda, a característica sazonal da produção, que apresenta redução superior a $60 \%$ na estação de inverno. Esse baixo desempenho zootécnico deve-se a diversos fatores, tais como o grande número de animais não especializados na produção de leite e as práticas de manejo inadequadas para o gado leiteiro, sendo isso consequência de o estado ser tradicionalmente produtor de gado de corte e da forte influência das práticas de manejo adotadas nessa atividade pecuária.

A pouca especialização da atividade leiteira praticada em Mato Grosso do Sul traz consequências negativas para a Cadeia Produtiva do Leite, como: alta sazonalidade de produção de matéria-prima para a indústria de laticínios e, consequente, volatilidade de preços; dificuldade de gerenciamento e planejamento da produção pecuária e industrial; desestímulo aos produtores que querem se especializar na pecuária leiteira, devido à não remuneração diferenciada para um leite de melhor qualidade; difusão de práticas de manejo não adequadas para a produção de leite; baixo conhecimento de técnicas agronômicas para a produção de alimentos específicos para o gado leiteiro; ineficiência do controle zootécnico do rebanho (SIMÕES et al., 2009).

Em comparação aos demais estados brasileiros, Mato Grosso do Sul apresenta um dos menores preços pagos ao produtor de leite (CEPEA, s.d.), sendo isso reflexo da baixa produção individual de leite, da precária conservação do leite e da inadequada logística de transporte. A pequena produção individual de leite dificulta a instalação de tanques de resfriamento e contribui para a manutenção das linhas de leite em tambores, o que leva à redução da qualidade microbiológica do produto. Quanto à logística de transporte, ressaltam-se as grandes distâncias a serem percorridas, o baixo volume coletado e as condições deficientes das estradas. Nesse sentido, a produção de derivados lácteos, como queijos, requeijão e doce de leite, normalmente confeccionados nas propriedades e vendidos de maneira informal, possibilita um aumento na renda da família, especialmente nos assentamentos rurais.

Dessa forma, produção de leite em Mato Grosso do Sul (MS) apresenta um crescimento vegetativo (IBGE, s.d.). No entanto em MS há um grande potencial para o desenvolvimento da pecuária leiteira em sistema de pastejo que poucos estados no cenário nacional vislumbram. MS detém terras propícias, clima favorável e disponibilidade de grãos e subprodutos para alimentação do rebanho, fatores que o credenciam a produzir leite com elevada competitividade (OLIVEIRA; LUZ, 2014). De acordo com Simões et al. (2009) a migração de sistemas produtivos mistos de bovinocultura de corte e leite para sistemas especializados e com ganhos de escala podem tornar a atividade leiteira em Mato Grosso do Sul economicamente atrativa e sustentável no longo prazo.

Segundo dados do último Censo Agropecuário, MS possui 64.862 propriedades rurais, destas 41.104 (63\%) são de origem da agricultura familiar. Em relação à orientação técnica, $61 \%$ das propriedades rurais nunca receberam nenhum tipo de assistência, 22\% 
recebem ocasionalmente e apenas $17 \%$ recebem regularmente (IBGE, s.d.).

Quanto à estrutura fundiária de Mato Grosso do Sul, esta é composta por grandes propriedades rurais, principalmente na região do Pantanal. Entretanto destaca-se que, paralelo a esta estrutura tipicamente concentrada, encontram-se ao longo de todo o seu território assentamentos rurais coletivos caracterizados por pequenas propriedades e com uso intensivo de mão de obra familiar. Segundo os dados do último Censo Agropecuário, $66 \%$ dos estabelecimentos agropecuários de MS têm menos de 100 hectares e $21 \%$ menos de 10 hectares; além disto, 63\% das propriedades rurais são classificadas como agricultura familiar, e estas possuem apenas $4 \%$ das terras ocupadas. Para esse grupo de produtores rurais, a atividade leiteira é uma das melhores alternativas de diversificação produtiva, pois esta se adapta a pequenas áreas e, principalmente, proporciona um fluxo de caixa contínuo para as famílias.

Diante desse panorama, a assistência técnica torna-se uma condição sine qua non para a potencialização da pecuária leiteira em Mato Grosso do Sul. Nesse sentido a Universidade Estadual do Mato Grosso do Sul (UEMS), por meio do Programa de Capacitação Técnica Aplicada a Pecuária Leiteira (RIO DE LEITE), avaliou o impacto econômicosocial da assistência técnica personalizada a um grupo de produtores de leite, pertencentes ao Assentamento Coletivo Rural Rio Feio, no município de Guia Lopes da Laguna, MS. Objetivou-se, portanto, demonstrar como o processo de assistência técnica foi implantado desde sua concepção, bem como os resultados zootécnicos obtidos.

\section{Material e métodos}

Para atender ao objetivo proposto, a UEMS / Unidade Universitária de Aquidauana (UEMS/UUA) propôs uma alternativa de um programa de assistência técnica a produtores de leite, essencialmente de cunho familiar. Oportunizada por um edital do FINEP/MDA/CNPq, a UEMS em parceria com a Universidade Federal de Mato Grosso do Sul (UFMS) e com a Secretaria de Estado de Meio Ambiente, do Planejamento, da Ciência e Tecnologia (SEMAC) de MS, conseguiu aportes financeiros para conduzir sistematicamente o processo de inovação tecnológica em alguns municípios de Mato Grosso do Sul pertencentes ao Território da Cidadania da Reforma, abrangendo os municípios de: Anastácio, Bela Vista, Guia Lopes da Laguna, Nioaque e Sidrolândia.

Assim, este artigo demonstra o processo de assistência técnica, desde sua concepção até a apresentação dos resultados, no Assentamento Rio Feio no município de Guia Lopes da Laguna. A escolha da localidade para a realização da experiência se deu em função da decisão do Colegiado do Território da Cidadania. Segundo o Instituto Nacional de Colonização e Reforma Agrária (INCRA), este assentamento foi criado em 1998 por meio de desapropriação de 2.344 hectares que foram distribuídos para 72 famílias em lotes com média de 32,5 hectares.

O projeto foi estruturado em quatro fases com o intuito de otimizar as diversas atividades necessárias para sua implementação, bem como para facilitar a designação das responsabilidades de cada membro da equipe de coordenação. Essa equipe contou com a participação ativa de professores da UEMS/UUA e da UFMS. As fases desde sua concepção até a conclusão foram: atividades técnicas, atividades políticas, atividades burocráticas e reuniões de articulação.

A fase de atividades técnicas contemplou: a elaboração e ministração de treinamento do técnico de campo; o diagnóstico, planejamento, execução e controle das atividades em cada propriedade rural; a realização de eventos técnicos; e a implantação de uma Unidade Demonstrativa de Produção de Leite (UDPL), comumente designada de vitrine tecnológica. É importante ressaltar que a Assistência Técnica foi realizada por um Zootecnista contratado (bolsista do CNPq), que ficou responsável por um grupo de 30 produtores ao longo de 12 meses.

O Zootecnista foi selecionado em edital público e, após sua contratação, foi feito o treinamento teórico-prático de 84 horas direcionado às tecnologias prioritárias a serem introduzidas nos sistemas de produção do público alvo, destacando-se: controles zootécnicos e econômicos; manejo reprodutivo; manejo sanitário; uso do sistema de posicionamento global (GPS) e construção de mapas; 
nutrição de bovinos leiteiros; implantação e manejo de pastagem e capineiras; e manejo de ordenha e raças leiteiras.

As visitas do Zootecnista às propriedades assistidas ocorreram quinzenalmente, sendo as demandas específicas resolvidas com visitas mais frequentes. Além da assistência técnica, o grupo de produtores atendido também recebeu informações zootécnicas por meio de cursos de capacitação (realizados em parceira com o Serviço Nacional de Aprendizagem Rural - SENAR/MS), dias de campo e das visitas mensais dos professores coordenadores do projeto, com o objetivo de orientar, corrigir e auxiliar os produtores e o Zootecnista responsável pelo grupo. Pelo fato da fase de assistência técnica do projeto ter sido de apenas 12 meses, priorizaram-se as intervenções técnicas que demonstrassem resultados em curto prazo. Nesse sentido, optou-se em priorizar a implantação e/ou manejo de pastagens em sistema rotacionado para as vacas em lactação, das capineiras (cana-de-açúcar) para suplementação volumosa na época seca do ano, do manejo de ordenha e do gerenciamento zootécnico e econômico da atividade.

As mudas de cana-de-açúcar necessárias para o plantio das capineiras foram doadas por uma unidade industrial de etanol, localizada próxima ao assentamento, e o transporte das mudas foi efetuado gratuitamente pela Prefeitura Municipal. O calcário, adquirido de uma empresa produtora circunvizinha ao município, também foi disponibilizado pela prefeitura. No plantio da cana-de-açúcar, além dos fertilizantes, recomendou-se, também, a aplicação de inseticida para combater o ataque de cupins.

A implantação da UDPL teve o objetivo de criar um ambiente onde os produtores do grupo pudessem visualizar o manejo das pastagens para as vacas leiteiras e replicar as técnicas em suas propriedades com a orientação do técnico. A UDPL foi implantada numa das propriedades atendidas, e os critérios para decisão da mesma foram a localização, o empenho e a experiência do produtor na atividade leiteira, possuir residência fixa na propriedade; e que a principal renda familiar fosse oriunda da produção de leite. $\mathrm{Na}$ propriedade que recebeu a UDPL foram disponibilizados gratuitamente pelo projeto calcário, adubos, sementes da gramínea
Panicum maximum cv. Mombaça, herbicidas e cupinicidas. A prefeitura forneceu o trator, os implementos agrícolas e o combustível, e o produtor ficou responsável pela construção da cerca elétrica.

No diagnóstico inicial de cada propriedade, foram identificadas as áreas destinadas à pecuária leiteira, a existência e estado de conservação de máquinas e equipamentos, as instalações e benfeitorias e o rebanho. Foi efetuado, também, um diagnóstico da produção e produtividade dos animais, bem com o perfil socioeconômico do produtor e sua família.

Após a identificação das principais características socioeconômicas e técnicas das propriedades atendidas, foi realizado um planejamento estratégico personalizado, levando-se em consideração o mínimo a ser produzido para atingir o ponto de equilíbrio econômico, e ainda as necessidades específicas de cada produtor. Apregoou-se um planejamento de produção de forragens que fosse capaz de suportar um rebanho que gerasse uma produção de pelo menos 3.000 litros/ ha/ ano considerando a área da propriedade destinada à atividade leiteira, as possibilidades financeiras, infraestrutura e capacidade suporte da propriedade, conforme a metodologia proposta por Simões et al. (2012).

Depois de haver um consenso entre o técnico e produtor a respeito do planejamento, foram delimitadas as áreas destinadas ao pastoreio das vacas em lactação e do local para implantação da cana-de-açúcar. Para tal foram realizadas coletas de amostras de solo para recomendação da calagem e adubação. Os locais tiveram os perímetros demarcados com o aparelho Sistema de Posicionamento Global (GPS) e, então, foi elaborado um mapa da área com a sugestão de divisões em piquetes com auxilio do software específico para desenhos arquitetônicos $\mathrm{O}$ número e o tamanho dos piquetes foram calculados considerando a espécie forrageira definida, seu período de descanso e a taxa de lotação em unidades animal por hectare (UA/ha).

A fase de Atividades Políticas concentrou as ações de construção das parcerias com a Prefeitura e respectivas secretarias de governo. Foi celebrado um convênio de cooperação entre a Prefeitura, UEMS, UFMS e SEMAC no intuito de estabelecer as obrigações e direitos 
de cada parte. Destaca-se que a prefeitura ficou encarregada de ceder o combustível para o deslocamento do técnico (200 litros/mês), bem como apoio de mecanização para preparo do solo e plantio de áreas de pastagem e capineiras. Além disso, a prefeitura municipal designou um servidor do seu quadro efetivo para manter um canal de comunicação com o técnico do projeto e a equipe da coordenação.

A fase de atividades burocráticas envolveu, principalmente, os procedimentos de compras (licitações) dos materiais permanentes e insumos necessários para viabilizar a execução do projeto, além da elaboração de documentos, tais como os ofícios, convites, convênios etc.

A fase de Reuniões de Articulações aconteceu em diversos momentos, ora com as prefeituras, ora com os produtores de leite e, às vezes, com ambos. As reuniões específicas com os produtores seguiram a sequência: sensibilização com apresentação da proposta de trabalho; cadastros de interessados em participar da assistência técnica; acompanhamento dos resultados; encerramento das atividades e prestação de contas. Nas reuniões de sensibilização foram esclarecidas todas as informações necessárias para que o trabalho decorresse da melhor forma possível destacando-se os direitos e deveres dos produtores atendidos.

\section{Resultados e discussão}

A estrutura fundiária de Mato Grosso do Sul historicamente é atrelada ao modelo de produção em grandes propriedades rurais e essencialmente com bovinocultura de corte. Entretanto esse modelo de monocultura extensiva é incompatível com uma grande parcela de produtores rurais de pequenas propriedades. Desse modo, os produtores e seus familiares pertencentes ao Assentamento Rural Rio Feio idealizam suas propriedades rurais como as dos grandes fazendeiros da região, e por décadas utilizaram erroneamente a terra e as pastagens, por acreditarem que os melhores resultados econômicos da atividade são obtidos com a utilização de grandes invernadas, em sistema de pastoreio contínuo, sem suplementação na época seca e com elevado número de cabeças de gado, em sua maioria animais de dupla aptidão (corte e leite). Esse manejo extensivo não especializado, além de ocasionar efeitos deletérios na qualidade e durabilidade da pastagem, obriga continuamente os proprietários a trabalharem com arrendamentos (aluguel) de terras de terceiros, já que as suas tornam-se insuficientes ao longo do tempo.

No longo prazo, isso acarreta índices zootécnicos medíocres, o insucesso financeiro da atividade leiteira e, consequentemente, a venda da posse do lote (terra recebida pelo sistema de reforma agrária), gerando, assim, uma rotatividade de famílias em uma mesma propriedade rural. Destaca-se que, frequentemente os produtores atendidos pelo projeto não eram os primeiros donos designados pelo processo de distribuição dos lotes da reforma agrária.

O diagnóstico inicial de cada propriedade evidenciou que os produtores do Assentamento Rio Feio caracterizam-se por terem faixa etária elevada, normalmente superior a 50 anos, além disso, pelo menos um membro da família, geralmente o marido, trabalha na cidade, ou em outra propriedade rural, a fim de trazer recurso financeiro externo para a subsistência. Outro ponto observado é que a baixa perspectiva da atividade leiteira faz com que os filhos, assim que atinjam a maioridade, deixem o ambiente familiar para morar na cidade, com a promessa de emprego, maior renda e melhor qualidade de vida. Nesse ciclo, reduz-se ainda mais a disponibilidade de mão de obra familiar dentro da propriedade, o que obriga a esposa e os filhos menores a assumirem as tarefas dos homens.

Um fato curioso citado pelos produtores é que muitos deles estão aguardando a aposentaria do governo e, quando isso ocorrer, deixarão de produzir leite, alegando que estão velhos e cansados, e a pecuária leiteira exige muito trabalho, dedicação e esforço físico. Toda essa conjuntura faz com que os produtores não se sintam motivados a investir na atividade, com reflexos diretos nos resultados obtidos com a assessoria técnica.

Nesse assentamento, as pastagens são formadas por gramíneas de porte baixo, na maioria das vezes por estoloníferas ou semiprostradas, como o capim Brachiaria spp., especialmente das cultivares decumbens, humidicola, ruziziensis etc. $\mathrm{Na}$ maior parte dos casos, as pastagens estão degradadas e com grande infestação de plantas nativas. A água 
dos animais é geralmente disponibilizada por meio de açudes, abastecidos somente com a água das chuvas, com consequente comprometimento da qualidade, especialmente no período de seca, tendo em vista que os animais entram no açude para se refrescarem e acabam frequentemente urinando e defecando nesse local.

O padrão genético do rebanho, também não é adequado para produção de leite. Segundo relato dos produtores, logo após o recebimento da posse do lote, a liberação dos recursos financeiros pelo governo federal (financiamentos PRONAF) para a compra de gado estava vinculada à aquisição de vacas leiteiras, em especial da raça Girolando. Todavia os reprodutores utilizados desde o início, em mais de $80 \%$ das propriedades, eram da raça Nelore, portanto, com genética de gado de corte. Assim, com o passar dos anos, as filhas e netas cruzadas continuamente com touro Nelore foram perdendo a sua aptidão leiteira.

A opção de uso do touro Nelore ocorre pela valorização da venda do bezerro, todavia inviabiliza a sustentabilidade da atividade leiteira, pois, para aumentar a produção diária, há necessidade de elevar o número de matrizes mantidas na propriedade. Esse aumento gera superlotação da propriedade fazendo com que não haja alimento suficiente para o rebanho e obrigando o produtor a arrendar (alugar) mais pastagens de terceiros, mesmo durante o período de primavera-verão. A prática de arrendamento é uma unanimidade entre os produtores assentados e diminui significativamente a margem de lucro da atividade leiteira, obrigando os produtores a deixar a atividade no longo prazo.

Na região do Assentamento Rio Feio, o preço do arrendamento é, em média, $\mathrm{R} \$ 15,00$ por animal/mês. Assim, o produtor que tem 10 cabeças em arrendamento tem uma despesa mensal de $R \$ 150,00$, o que totaliza $R \$$ $1.800,00$ por ano que poderiam ser reinvestidos em adubações, manutenção de cercas dentro de sua própria área produtiva.

Devido ao elevado número de animais e a baixa receita originária do leite, identificouse uma suplementação mineral deficitária, sendo que $60 \%$ dos produtores fornecem apenas sal branco ou este misturado, em proporções variadas, com o sal mineralizado. $\mathrm{Na}$ época de inverno, verificou-se que mais de $70 \%$ dos produtores também não têm costume de suplementar o rebanho, e quando o fazem, em geral, é com ração concentrada, que, apesar do custo ser bem mais elevado, é mais fácil de ser fornecida que a cana-deaçúcar, especialmente por não precisar ser diariamente cortada, transportada, triturada e colocada no cocho.

Observou-se ainda que, apesar da totalidade das propriedades possuírem sala de ordenha, devido a uma obrigatoriedade imposta pelo governo federal para liberação dos lotes de terra e dos respectivos financiamentos, o leite é ordenhado sem os cuidados sanitários previstos na Instrução Normativa $\mathrm{n}^{\circ} 62$ (MAPA, 2011), pois a maioria das instalações não possui o piso concretado nem água corrente para lavagem dos tetos e das mãos do ordenhador. A higienização dos tetos com agente sanitizante, como cloro ou amônia quaternária, também não é efetuada, e a ordenha é realizada somente no período da manhã, já que o manejo é efetuado com a presença do bezerro. O leite é armazenado em tambores plásticos de 50 litros, sendo imediatamente enviado para o tanque de resfriamento coletivo e posterior comercialização com laticínios. Um único produtor beneficiava o leite em sua propriedade, sendo o doce de leite vendido em mercados locais, tendo em vista que ele possuía a autorização do Serviço de Inspeção Municipal (SIM).

Devido ao curto período de assessoria técnica (12 meses), o objetivo principal do planejamento foi potencializar o uso da pastagem para as vacas em lactação, de modo a evitar a superlotação, reduzir a incidência de plantas invasoras e obter a máxima produção de leite por hectare. Nesse sentido, uma das grandes dificuldades encontradas no processo de adoção de tecnologias, em quase a totalidade das propriedades atendidas, foi a falta de dinheiro para o investimento mínimo na atividade. Assim, as ações realizadas para otimizar o uso das pastagens foram em ordem de prioridade: $1^{\circ}$ ) efetuar a divisão da pastagem com cerca elétrica, com um número de piquetes não inferior a 29 , de modo a promover um descanso da forrageira e aumentar a capacidade de resiliência; $2^{\circ}$ ) corrigir o solo e realizar as adubações de reposição para manter a fertilidade compatível com as exigências da cultura; e $3^{\circ}$ ) implantar outro tipo de forrageira mais 
produtiva, com maior potencial de biomassa comestível e com melhor qualidade nutricional, como o Panicum maximum cv. Mombaça ou Tanzânia, o Cynodon dactylon cv. Tifton e a Brachiaria brizantha cv. Piatã ou MG5, em substituição à gramínea existente. Essa última medida foi tomada somente nos casos em que a pastagem estava totalmente degradada, sem condições de recuperação, ou quando o produtor tinha interesse e condições para realizar a substituição.

Os resultados revelam, ainda, que apenas $27 \%$ das propriedades atendidas adotaram plenamente as recomendações sobre a formação e manejo das pastagens. Para essas propriedades, as mudanças realizadas nesse aspecto permitiram que houvesse um incremento médio de 3.233 litros/ha/ano, ou seja, saíram de 1.032 litros/ha/ano no início do projeto para 4.265 litros/ha/ano após 12 meses. Ressalta-se que a produtividade inicial da terra foi mensurada considerando toda a área da propriedade, uma vez que as vacas em lactação ficavam distribuídas junto com as outras categorias e que a produtividade final foi mensurada somente nas áreas de pastejo intensivo para as vacas em lactação. Nesta análise, pode-se afirmar que, além dos ganhos de produtividade e melhoria qualitativa do uso da terra, houve também, um ganho mensurado pelo custo de oportunidade da área liberada pela intensificação, uma vez que possibilitou ao produtor não mais fazer uso do arrendamento de terras de terceiros para colocar parte do seu gado.
Devido à precariedade da maioria das propriedades em relação ao manejo de ordenha, as recomendações de manejo sanitário limitaram-se em melhorar as condições de higiene, como a lavagem das mãos e desinfecção dos tetos com água clorada antes da ordenha, e consequentemente a qualidade do leite. Ressalta-se que essa tecnologia, apesar de simples, não foi adotada pela maioria $(65 \%)$ dos produtores, com justificativa da ausência de torneira no estábulo e pelo custo para canalização da água. Outro fato que contribuiu para não adoção dessa técnica é a crendice popular de que o próprio bezerro ao apojar a vaca (mamar) já faz a limpeza do teto.

Outras recomendações, como troca de reprodutor da raça nelore por um touro leiteiro, implantação de duas ordenhas diárias, desmama precoce, mineralização do rebanho, criação dos animais separados por categoria, inseminação artificial, arraçoamento em função da produtividade, implantação do calendário sanitário do rebanho, pesagem dos animais, controle zootécnico do rebanho, disponibilização de água em pilheta etc., foram efetuadas conforme a aceitabilidade e necessidade de cada produtor (Tabela 1). Somente 39\% dos produtores acataram plenamente essas recomendações, sendo as justificativas relacionadas com a falta de recursos financeiros, o aumento do tempo gasto com a atividade e falta de visualização de retorno econômico no curto prazo com a implantação da referida técnica. 
Tabela 1 - Inovações tecnológicas adotadas pelos produtores participante

\begin{tabular}{|c|c|c|c|}
\hline \multirow{2}{*}{ Recomendações } & \multicolumn{3}{|c|}{ \% de Adoção Tecnológica } \\
\hline & Não & Parcialmente & Total \\
\hline Adubação da pastagem & 64 & - & 36 \\
\hline Análise de solo & 27 & - & 73 \\
\hline Arraçoamento em função da produção de leite & 82 & - & 18 \\
\hline Calagem do solo & - & - & 100 \\
\hline Calendário sanitário & - & 82 & 18 \\
\hline Controle da produtividade das vacas & 18 & 55 & 27 \\
\hline Controle diário da produção & - & 9 & 91 \\
\hline Controle financeiro & - & 100 & 0 \\
\hline Manejo de ordenha & 73 & 9 & 18 \\
\hline Manejo de pastagem & 46 & 27 & 27 \\
\hline Mineralização do rebanho & - & 55 & 45 \\
\hline Mochação e identificação de bezerras & 82 & 9 & 9 \\
\hline Participação em cursos e dias de campo & 46 & 27 & 27 \\
\hline Piqueteamento da pastagem & 45 & 10 & 45 \\
\hline Plantio da cana de açúcar & 27 & 18 & 55 \\
\hline Plantio e recuperação da pastagem & 36 & 19 & 45 \\
\hline Segunda ordenha diária & 36 & 36 & 28 \\
\hline Uso de bebedouro ou pilheta & - & 73 & 27 \\
\hline Substituição de vacas velhas ou sem potencial leiteiro & 82 & - & 18 \\
\hline Tratos culturais na pastagem e capineira & 36 & 36 & 28 \\
\hline Troca do touro ou uso de Inseminação Artificial & 27 & 55 & 18 \\
\hline Uso cana corrigida com uréia e sulfato de amônia & 91 & 9 & 00 \\
\hline Média & 37 & 24 & 39 \\
\hline
\end{tabular}

Diante da resistência e da realidade de escassez de informações dos produtores a respeito da sua atividade, considera-se que a própria implantação dos controles zootécnicos e econômicos básicos constituiu uma inovação tecnológica importante e extremamente significativa para os produtores assistidos. Observou-se 100\% de realização parcial do controle financeiro (controle de caixa) e 91\% do controle diário da produção (Tabela 1). Ressalta-se que essas informações, nunca antes medidas pelos produtores, possibilitaram a estes um maior conhecimento sobre a propriedade e uma conscientização da importância da adoção de outras inovações tecnológicas.

Ao longo da execução do projeto, foram realizados cursos sobre manejo do rebanho leiteiro, em parceria com o SENAR/MS. Trimestralmente foram realizados Dias de Campo, sendo as atividades efetuadas na
UDPL e nas demais propriedades atendidas. Também foi efetuada uma visita no Centro de Referência de Produção e Beneficiamento de Leite do Estado de Mato Grosso do Sul, localizado na UEMS/UUA, com o intuito de estimular a adoção de tecnologias.

Durante a execução do projeto ocorreu desistência e/ou o desligamento de $61 \%$ dos produtores, sendo que destes, $41 \%$ alegaram desistir por ter uma oportunidade de trabalho melhor na cidade ou em outra fazenda próxima (Tabela 2). Assim, o elevado custo de oportunidade da mão de obra ${ }^{1}$ retirou o

\footnotetext{
1 Esse custo refere-se às oportunidades oferecidas em termos de remuneração salarial em uma realidade urbana ou em outra fazenda exercendo a mesma atividade. Geralmente o custo de oportunidade da mão de obra mede-se em função da qualificação e dos anos de estudo. Como geralmente a escolaridade em assentamentos rurais é baixa, é razoável e coerente com admitir o valor do salário mínimo como remuneração alternativa.
} 
principal membro da família, responsável pela força de trabalho da atividade leiteira, ficando na maioria dos casos somente a esposa e filhos responsáveis por uma produção de subsistência. Nesse modelo de produção, o número de vacas ordenhadas foi reduzido e o manejo dos animais era realizado sempre visando minimizar o trabalho. O não cumprimento mínimo das recomendações técnicas foi responsável por $17 \%$ dos desligamentos compulsórios.

Tabela 2 - Principais motivos para não permanência dos produtores

\begin{tabular}{lc}
\hline Motivos & \% \\
\hline Elevado custo de oportunidade da mão & 41 \\
de obra & 17 \\
Não cumpriu as recomendações técnicas & 12 \\
Problemas de saúde ou falecimento & 12 \\
Expectativa de ganhar recursos & 6 \\
governamentais & 6 \\
Problemas com de mão de obra & 0 \\
Dificuldades financeiras & 18 \\
Outros & $100 \%$ \\
\hline Total
\end{tabular}

Em relação à produção e à produtividade das vacas no início da assessoria técnica, observou-se uma média de 30 litros/dia e 2,1 litros/vaca/dia, respectivamente. Após 12 meses de assistência técnica, foi observada uma produção média diária máxima de 46 litros/dia, e a menor foi de 15 litros/dia, configurando heterogeneidade nas escalas de produção dos respectivos sistemas. Em relação à produtividade, observou-se uma média de 6,3 litros/vaca/dia, com valor máximo de 10,5 e mínimo de 4 litros/vaca/dia, caracterizando os diferentes níveis tecnológicos relacionados ao potencial genético, qualidade e disponibilidade de alimentos e de manejos das vacas e bezerros.

Ressalta-se que os maiores ganhos individuais das vacas ocorreram devido à seleção dos animais e à maior disponibilidade de alimento, tendo em vista que a pastagem foi melhorada. A venda das vacas sem potencial genético para custear os gastos com adubos, mourões e arame para a divisão da pastagem também contribuiu para melhorar os resultados, tendo em vista a diminuição da taxa de lotação da propriedade.
A Unidade Demonstrativa de Produção de Leite (UDPL) implantada no assentamento atendido foi composta de três hectares de Panicum maximum cv. Mombaça subdivididos em 30 piquetes, projetados para ter um dia de pastejo e 29 dias de descanso. Utilizou-se cerca elétrica de dois fios para subdivisão interna e convencional na periférica. Na pastagem foi deixado um bosque para descanso dos animais, com bebedouro e saleiro comunitário. A taxa de lotação utilizada foi de cinco Unidades Animal por hectare (UA/ha) e utilizadas somente vacas em lactação. Quanto às operações de formação da nova pastagem da UDPL, nota-se que inicialmente efetuou-se destoca e limpeza da área, com subsequente dessecação da forrageira anterior, utilizando-se o herbicida glifosato, e em seguida realizou-se a distribuição de calcário e os procedimentos de aração, duas gradagens e nivelamento. Foram utilizados $15 \mathrm{~kg}$ de sementes por hectare e aplicou-se, em função da análise de solo, o calcário, fósforo e potássio no plantio e nitrogênio e potássio como cobertura. $\mathrm{Na}$ UDPL também foi implantado um hectare de cana-de-açúcar, para suprir as necessidades do rebanho durante a época de seca.

O primeiro pastejo da UDPL ocorreu no início de março com taxa de lotação por hectare de 5,93 unidades animal (UA), ou seja, de 16 vacas, com peso corpóreo de 500 $\mathrm{kg}$, nos três hectares destinados ao pastoreio. Taxas de lotação semelhantes para o capim mombaça foram observadas por Cândido et al. (2005), com médias de 4,6; 5,2 e 4,9 UA/ ha para três períodos de descanso. Corroborando, Garcia et. al. (2011) encontraram uma taxa de lotação de 4,4 UA/ha em diferentes disponibilidades da forragem.

Os custos de implantação do sistema de pastejo da UDPL estão descritos na Tabela 3 , no qual o custo total incluindo o custo de financiamento (PRONAF, 2,5\% ao ano) foi de R\$23.771,00 Simulando um tempo de amortização de cinco anos, o custo diário para pagar o investimento foi de $R \$ 11,51$. Sendo o preço médio pago ao produtor de $\mathrm{R} \$ 0,50$ por litro de leite, será necessário o incremento médio de cerca de 23 litros/dia, o que corresponde a apenas 1,92 litros/vaca/dia, para cada uma das 12 vacas, para se pagar o investimento inicial e manutenção das pastagens. 
Tabela 3 - Custo de implantação de três hectares de capim Mombaça e simulação de amortização de custos da Unidade Demonstrativa de Produção de Leite

\begin{tabular}{llr}
\hline Implantação de Pastagem (3 ha) & R\$/ha & \multicolumn{1}{c}{ Total } \\
\hline Mecanização & $2.045,00$ & $6.135,00$ \\
Insumos & $2.398,62$ & $7.195,86$ \\
Cerca elétrica (2 fios) & $2.014,50$ & $5.239,50$ \\
\hline Custo Total de Implantação da pastagem & $6.458,12$ & $18.570,36$ \\
\hline \hline Taxa de juros (aa) & & $2,50 \%$ \\
Tempo para amortização (anos) & 5 \\
Custo de Implantação + Juros (R / ha) & & $7.306,77$ \\
Custo de Implantação + Juros (R\$/U.D.) & $21.010,65$ \\
\hline \hline Tempo para amortização (anos) & & 5 \\
Custo por dia (R\$/dia) & & 11,51 \\
Preço do Leite (R \$litro) & & 2,50 \\
Incremento diário da produção para pagar investimento (L/dia) & & 4,03 \\
Taxa de Lotação (vacas/ha) & & 12,00 \\
Total de vacas (vacas no sistema) & 1,92 \\
Incremento da produção para pagar investimento (L/vaca/dia) & &
\end{tabular}

Além do benefício direto da UDPL, em termos de produção de leite, observaram-se ganhos na conservação do solo e da água nas áreas de pastagem, melhorias na condição corporal das vacas e, o mais importante, a realização pessoal do produtor rural e sua família.

\section{Conclusões}

Este estudo avaliou o efeito da assistência técnica personalizada a um grupo de produtores de leite, pertencentes ao Assentamento Rural Coletivo Rio Feio, no município de Guia Lopes da Laguna, MS. Teve como objetivo demonstrar como o processo de assistência técnica foi implantado desde sua concepção, bem como os resultados obtidos a curto e médio prazo.

Os produtores do Assentamento, apesar de serem carentes de informação tecnológica sobre a bovinocultura leiteira, possuem elevado grau de resistência às implantações de qualquer tipo de inovação tecnológica que gere mudança na rotina dentro da propriedade. A cultura da pecuária bovina de corte dificulta a inserção de novos processos produtivos capazes de gerar autossuficiência para as propriedades rurais produtoras de leite de origem familiar.

Os produtores que adotaram, mesmo que parcialmente, as recomendações técnicas obtiveram respostas positivas no aumento da produtividade dos animais, nos ganhos por área, expresso em litros de leite por hectare ao ano, e no custo de oportunidade da terra.

A implantação de Unidades Demonstrativas foi uma ferramenta convincente e de difusão de tecnologias, principalmente quando demonstrada a sua viabilidade econômica.

Este estudo permitiu identificar a exiguidade de políticas de assistência técnica efetiva no assentamento rural estudado. Nesse sentido, é possível compreender que os governos necessitarão envidar esforços e recursos para que a atividade de bovinocultura leiteira deixe de ter um caráter de subsistência e que o leite possa ser comercializado dentro dos padrões higiênicos e sanitários preconizados pelos órgãos de controle.

\section{Referências}

CÂNDIDO, M. J. D.; ALEXANDRINO, E.; GOMIDE, C. A. M.; GOMIDE, J. A.; PEREIRA, W. E. Período de descanso, valor nutritivo e desempenho animal em pastagem de Panicummaximum cv. Mombaça sob lotação intermitente. Revista Brasileira Zootecnia, Brasília, v. 34, n. 5, p. 1459-1467, 2005.

CENTRO DE ESTUDOS AVANÇADOS EM ECONOMIA APLICADA - CEPEA - DA ESALQ/USP. [s.d.]. Disponível em: <www.cepea.esalq.usp.br>. Acesso em: 12 maio 2013.

FOOD AND AGRICULTURE ORGANIZATION OF THE UNITED NATIONS - FAO. [s.d.]. Disponível em: <www.fao.org>. Acesso em: 24 maio 2013.

GARCIA, C. S.; FERNANDES, A. M.; FONTES, C. A. A.; VIEIRA, R. A. M.; SANT' ANNA, N. F.; PIMENTEL, 
V. A. Desempenho de novilhos mantidos em pastagens de capim-elefante e capim-mombaça. Revista Brasileira de Zootecnia, Brasília, v. 40, n. 2, p. 403-410, 2011.

INSTITUTO BRASILEIRO DE GEOGRAFIA E ESTATÍSTICA - IBGE. [s.d.]. Disponível em: <www.ibge.gov. br>. Acesso em: 16 jan. 2013.

INSTITUTO NACIONAL DE COLONIZAÇÃO E REFORMA AGRÁRIA - INCRA. Disponível em: <http:/ / www.incra.gov.br>. Acesso em: 2 abr. 2013.

MADALENA, F. E. A Cadeia do leite no Brasil. In: MADALENA, F. E.; MATOS, L. L.; HOLANDA JÚNIOR, E. V. (Ed.). Produção de leite e sociedade. Belo Horizonte, MG: FEPMVZ, 2001. p. 1-26.

MINISTÉRIO DA AGRICULTURA, PECUÁRIA E ABASTECIMENTO - MAPA. Instrução Normativa $n^{\circ}$ 62, publicada em 29/12/2011. Disponível em: <www. jusbrasil.com.br/diarios/33395065/dou-secao-1-30-122011-pg-6>. Acesso em: 19 mar. 2013.
OLIVEIRA, M. V. M.; LUZ, D. F. Sistemas sustentáveis de produção de leite em Mato Grosso do Sul. In: ENCONTRO SOBRE ZOOTECNIA DO MATO GROSSO DO SUL - EZOOMS, 11., Campo Grande, MS, 2014. Anais... Campo Grande: EZOOMS - UFMS, 2014. p. 1-20.

SIMÕES, A. R. P.; SILVA, R. M.; OLIVEIRA, M. V. M. Avaliação econômica de três diferentes sistemas de produção de leite na região do Alto Pantanal Sul-mato-grossense. Agrarian, Dourados, MS, v. 2, n. 5, p. 153-167, 2009.

SIMÕES, A. R. P.; OLIVEIRA, M. V. M.; FIGUEIRÓ, R. N. Planejamento estratégico de propriedades leiteiras em sistema de pastejo. Dourados, MS: Editora UEMS, 2012. 54p. WEIVERBERG, S. L.; SONAGLIO, C. M. Caracterização da produção de leite no Estado de Mato Grosso do Sul. In: CONGRESSO DA SOCIEDADE BRASILEIRA DE ECONOMIA, ADMINISTRAÇÃO E SOCIOLOGIA RURAL, Campo Grande, MS, 2010. Anais... Campo Grande: SOBER, 2010. 